\title{
Aspirin before coronary artery surgery
}

\author{
William M. Whited, Erin M. Schumer, Mark S. Slaughter \\ Department of Cardiovascular and Thoracic Surgery, University of Louisville, Louisville, KY, USA \\ Correspondence to: Mark S. Slaughter, MD. University of Louisville, 201 Abraham Flexner Way, Ste 1200, Louisville, KY 40202 , USA. \\ Email: mark.slaughter@louisville.edu.
}

Submitted Jun 22, 2016. Accepted for publication Jun 29, 2016.

doi: $10.21037 /$ jtd.2016.08.05

View this article at: http://dx.doi.org/10.21037/jtd.2016.08.05

Myles and colleagues recently reported in the New England Fournal of Medicine the results from their Aspirin and Tranexamic Acid for Coronary Artery Surgery (ATACAS) study (1). This was a multicenter trial evaluating the effects of aspirin in patients undergoing coronary surgery. This study found no difference in the rates of bleeding complications or thromboembolic events, which contradict previous studies $(2,3)$.

The ATACAS trial randomly assigned patients undergoing coronary artery surgery to receive $100 \mathrm{mg}$ of aspirin or placebo. During this trial 2,100 patients were enrolled. Of these 2,100 patients, 1,047 were randomly assigned to receive aspirin and 1,053 were randomly assigned to receive placebo. Patients either received aspirin $100 \mathrm{mg}$ or placebo 1 to 2 hours prior to coronary artery surgery. The primary outcomes of the study were death and thrombotic events (myocardial infarction, stroke, pulmonary embolus, renal failure). The primary outcome occurred in $19.3 \%$ of the aspirin group and in $20.4 \%$ of the placebo group. There was also no difference observed in the rates of myocardial infarction or bleeding complications between the two groups.

There have been numerous papers written on the topic of pre-operative aspirin administration in patients undergoing cardiac surgery. A recent meta-analysis with a total of 13 different trials and over 2,300 patients did find that pre-operative aspirin reduced the incidence of perioperative MI but also lead to an increase in the rate of blood transfusions, bleeding, and surgical re-exploration (2). As the authors of the ATACAS trial point out, their study contradicts portions of this study. One potential reason for a difference between the two studies could be related to the dose used $(100 \mathrm{mg})$. The authors point out that this dose is known to be cardioprotective but could potentially have a decreased risk of bleeding compared with higher doses. The ATACAS trial was originally designed to evaluate the risk and benefits of aspirin and anti-fibrinolytic therapy in coronary artery surgery. As a result of the study design half of the aspirin group and half of the placebo group received tranexamic acid which could mitigate the number of patients with bleeding complication. This in combination with the fact that a portion of patients are resistant to aspirin (4), could potentially skew the data.

The use of pre-operative aspirin in cardiac surgery is undoubtedly a topic of debate. One has to weigh the potential risk of bleeding with the potential benefits of preventing thrombotic events. This study suggests that the administration pre-operative may not be critical. Similar to many clinical questions in medicine, answers are never easy or straightforward. There is data (5) to suggest patients should not take aspirin prior to valve surgery alone, particularly in patients without significant coronary artery disease. However in patients undergoing coronary artery surgery it remains less clear. It is certainly reasonable to continue aspirin in patients for whom a thrombotic event may be more likely including those patients with a history of previous MIs, deep vein thrombosis, or cerebrovascular accident. Given the data in this study, it is also acceptable to discontinue aspirin in patients at higher risk of a bleeding complication. In future studies, it would be helpful if platelet activity level would be measured pre-operatively that would help create subsets of patients based on their response and actual platelet inhibition level. Overall, this study does not resolve the issue of continuation of aspirin prior to coronary surgery and the ultimate clinical decision will continue to be made on a case-by-case basis most likely based on the program and individual physician experience.

\section{Acknowledgements}

None. 


\section{Footnote}

Provenance: This is an invited Editorial commissioned by the Section Editor Yi Lin (Department of Cardiovascular Surgery, Zhongshan Hospital Fudan University, Shanghai Institute of Cardiovascular Disease, Shanghai, China).

Conflicts of Interest: The authors have no conflicts of interest to declare.

Comment on: Myles PS, Smith JA, Forbes A, et al. Stopping vs. Continuing Aspirin before Coronary Artery Surgery. N Engl J Med 2016;374:728-37.

\section{References}

1. Myles PS, Smith JA, Forbes A, et al. Stopping vs. Continuing Aspirin before Coronary Artery Surgery. N

Cite this article as: Whited WM, Schumer EM, Slaughter MS. Aspirin before coronary artery surgery. J Thorac Dis 2016;8(9):2290-2291. doi: 10.21037/jtd.2016.08.05
Engl J Med 2016;374:728-37.

2. Hastings S, Myles P, McIlroy D. Aspirin and coronary artery surgery: a systematic review and meta-analysis. Br J Anaesth 2015;115:376-85.

3. Goldhammer JE, Marhefka GD, Daskalakis C, et al. The Effect of Aspirin on Bleeding and Transfusion in Contemporary Cardiac Surgery. PLoS One 2015;10:e0134670.

4. Petricevic M, Biocina B, Konosic S, et al. Impact of aspirin resistance on antiplatelet therapy management after coronary artery surgery. Eur J Cardiothorac Surg 2012;42:760-1; author reply 761.

5. Huang J, Donneyong M, Trivedi J, et al. Preoperative Aspirin Use and Its Effect on Adverse Events in Patients Undergoing Cardiac Operations. Ann Thorac Surg 2015;99:1975-81. 